\title{
Spectroscopic Study of Effects of Goethite Surfaces on the Simulated Maillard Reaction Forming Humic-like Substances*
}

\author{
Yuki Nakaya, ${ }^{\dagger}$ Katsuya Okada, Yudai Ikuno, and Satoru Nakashima \\ Department of Earth and Space Science, Graduate School of Science, \\ Osaka University, 1-1 Machikaneyama-cho, Toyonaka, Osaka 560-0043, Japan
}

(Received 8 January 2018; Accepted 15 September 2018; Published 6 October 2018)

\begin{abstract}
Progress of the simulated Maillard reaction for $0.1 \mathrm{~mol} \mathrm{~L} \mathrm{~L}^{-1}$ glycine and ribose mixture solution at $80^{\circ} \mathrm{C}$ for 0-7 days forming humic-like substances in the presence/absence of goethite was examined by ultraviolet-visible (UV-VIS) spectroscopy. $254 \mathrm{~nm}$ and $420 \mathrm{~nm}$ absorption intensities for the product solutions with goethite increased faster than for those without goethite, indicating enhancement of the reaction progress in the presence of goethite in several days at $80^{\circ} \mathrm{C}$. Adsorption onto goethite of reactants of the reaction were directly monitored by attenuated total reflection infrared (ATR-IR) spectroscopy with thin layers of goethite on the ATR crystal (ZnSe). IR spectral changes with time for the reactant solution $\left(0.1 \mathrm{~mol} \mathrm{~L}^{-1}\right.$ glycine and ribose mixture solution) on the goethite layer suggested fast adsorption within a few hours at room temperature of oxygenated components of glycine onto positively charged goethite surface. In situ heating ATR-IR kinetic measurements of humic-goethite interfaces will be useful for examining mechanisms of surface processes leading to reaction enhancement. [DOI: 10.1380/ejssnt.2018.411]
\end{abstract}

Keywords: Infrared absorption spectroscopy; Visible/ultraviolet absorption spectroscopy; Adsorption kinetics; Solid-liquid interfaces

\section{INTRODUCTION}

Solid-liquid interfaces are determining chemical and physical properties of organic and inorganic materials' surfaces in contact with liquids in various fields such as biology [1], hydrophilic substances [2], electrochemistry [3], friction [4], and electric devices [5]. In earth sciences, solid-liquid interfaces are crucial for dynamic behavior of earth systems, because most of reactions and transport of materials are occurring at mineral-water interfaces [6] Moreover, mineral surfaces have been reported to act as catalytic sites for various geochemical reactions (e.g. Hoffmann (1990) [7]; Wehrli (1990) [8]; Sulzberger (1990) [9]; Otsuka and Nakashima (2007) [10]). In this paper, an aqueous geochemical reaction in the presence of a mineral has been studied by taking an example of the simulated Maillard reaction between glycine and ribose forming humic-like substances in the presence of iron hydroxide, goethite.

"Humic substances" is a general term of polymerized high-molecular-weight organic matter whose structure is not defined [11]. Humic substances are the major organic components in the earth's surface environments and play key roles in interactions with environmental pollutants [12]. Adsorption of humic substances onto clay minerals is also important because it is responsible for stability and mobility of humic substances [13], thus concerning to those of the pollutants. However, various types of complex clay minerals are present in natural environments and characterization of their surfaces are not easy [14]. Some studies have simulated adsorption of humic substances to clay minerals by using iron hydroxide, goethite

\footnotetext{
* This paper was presented at the 8th International Symposium on Surface Science, Tsukuba International Congress Center, Tsukuba, Japan, October 22-26, 2017.

$\dagger$ Research Fellow of Japan Society for the Promotion of Science. ; Corresponding author: ynakaya@ess.sci.osaka-u.ac.jp
}

$(\alpha-\mathrm{FeOOH})$ (e.g. Weng et al. (2006) [13]; Otsuka and Nakashima (2007) [10]). It is one of representative inorganic soil constituents giving yellow-brownish colors of soils, and is the most stable phase in humid environments [15]. Its surface is positively charged at acidic to neutral pH conditions [16]. Otsuka and Nakashima (2007) [10] reported that humic substances decomposed faster in the presence of goethite. They suggested adsorption and oxidation of humic substances on goethite surfaces.

On the other hand, the Maillard reaction is a continuous browning reaction between an amino group and a carbonyl group producing polymerized brown organic compounds, melanoidins [17]. It has been studied mainly in food chemistry for changes in colors, flavors and nutritions of foods [18]. Formation processes of humic substances in aquatic or soil environments are considered to include the Maillard reaction of biogenic residues [19]. Therefore, the Maillard reaction has been studied in a few geochemistry researches for understanding time scales, amounts and properties of the reaction and products (e.g. Abelson (1978) [20]; Yamamoto and Ishiwatari (1989) [19]; Nakaya and Nakashima (2016) [21]; Nakaya et al. (2018) [22]). Some experimental works studied changes of bulk solution chemistry during the Maillard reaction in the presence of clay minerals (e.g. Taguchi and Sampei (1986) [23]; Arfaioli et al. [24]). They reported that reaction products and their formation rates have been modified by clay minerals. However, surface processes on clay minerals have not been examined.

In this study, effects of goethite on the simulated Maillard batch reaction progress at $80^{\circ} \mathrm{C}$ are examined by ultraviolet-visible (UV-VIS) spectroscopy. In addition, adsorption onto goethite at room temperature of the simulated Maillard reaction reactants is monitored by attenuated total reflection infrared (ATR-IR) spectroscopy. As reactants for the simulated Maillard reaction forming humic-like substances, glycine and ribose $\left(0.1 \mathrm{~mol} \mathrm{~L}^{-1}\right)$ were selected here based on our previous researches [21, 22]. 


\section{EXPERIMENTAL}

\section{A. Preparation of goethite}

Goethite samples were prepared after the methods of Schwertsmann and Cornell (2000) [25] and Otsuka and Nakashima (2007) [10]. While they used $\mathrm{Fe}\left(\mathrm{NO}_{3}\right)_{3}$ and $\mathrm{KOH}$ in the methods, we used $\mathrm{FeCl}_{3}$ and $\mathrm{NaOH}$ for avoiding remaining nitrate adsorbed on goethite surfaces and for possible future comparison with different ionic strength conditions.

$100 \mathrm{~mL}$ of $0.1 \mathrm{~mol} \mathrm{~L}{ }^{-1} \mathrm{FeCl}_{3}$ solution and $180 \mathrm{~mL}$ of 5 mol L ${ }^{-1} \mathrm{NaOH}$ solution were mixed and diluted to $2 \mathrm{~L}$ with pure water (MilliQ: Resistance $>18.2 \mathrm{M} \Omega \mathrm{cm}$ ). This solution with rapid precipitation of brownish suspension was subdivided into two polypropylene vessels $(1 \mathrm{~L}$ each) and incubated at $70^{\circ} \mathrm{C}$ for $60 \mathrm{~h}$. Then yellowish-brown precipitates were filtered using $0.2 \mu \mathrm{m}$ Millipore filter. They were washed by pure water three times and dried in an electric oven at $50^{\circ} \mathrm{C}$ for $4.5 \mathrm{~h}$.

In order to identify the obtained precipitates, small amounts of them were hand pressed on $\mathrm{Al}$ foil and measured by visible, Raman and infrared (IR) microspectroscopy. For visible and Raman micro-spectroscopy, a home-built micro-spectrometer was used [26]. Visible spectra were obtained in the wavelength region of 380 $850 \mathrm{~nm}$ by using a 150 lines/mm grating with the following conditions: $5 \mathrm{~s}$ of integration time; accumulation numbers of 12 ; with a dark field type objective lens $(5 \times)$. Raman spectra were obtained in the $50-1950 \mathrm{~cm}^{-1}$ range by using a 1200 lines/mm grating with the following conditions: $5 \mathrm{~s}$ of integration time; accumulation numbers of 12 ; with a $50 \times$ objective lens. IR microspectroscopic measurements were conducted by using an FT-IR micro-spectrometer (FTIR620 + IRT30, Jasco) [27-29]. IR spectral measurements were accumulated for 64 scans with a wavenumber resolution of $4 \mathrm{~cm}^{-1}$ in the 700-4000 $\mathrm{cm}^{-1}$ spectral range. The precipitates were also measured by X-ray diffractometry using MiniFlex (Rigaku). X-ray patterns were measured at a scanning speed of $2.0^{\circ}$ per minute with a measurement interval of $0.1^{\circ}$ in the $6.0^{\circ}-50.0^{\circ}$ angle range.

\section{B. The simulated Maillard reaction experiments with/without goethite}

In order to examine effects of goethite on the Maillard reaction processes, ultraviolet-visible (UV-VIS) spectroscopy for batch samples of $0.1 \mathrm{~mol} \mathrm{~L}^{-1}$ glycine + ribose solution heated at $80^{\circ} \mathrm{C}$ for $0-7$ days $(0-168 \mathrm{~h})$ was conducted.

$0.1 \mathrm{~mol} \mathrm{~L}^{-1}$ glycine + ribose mixture solution was subdivided into 16 polypropylene micro-tubes containing $1.0 \mathrm{~mL}$ of $0.1 \mathrm{~mol} \mathrm{~L}^{-1}$ glycine + ribose solution. For an experimental group including goethite (8 polypropylene micro-tubes), $5 \mathrm{mg}$ of goethite samples were added to $0.1 \mathrm{~mol} \mathrm{~L}^{-1}$ glycine + ribose solutions. Among 8 (without goethite) plus 8 (with goethite) polypropylene micro-tubes, two of them were kept at room temperature (heated for $0 \mathrm{~h}$ ) and the other two sets $(2 \times 7)$ were heated at $80^{\circ} \mathrm{C}$ in an electric oven for $24,48,72,96,120,144$, and
$168 \mathrm{~h}$ (1-7 days) in order to accelerate the reaction. After heating for each period, they were taken out from the oven and stored in a refrigerator $\left(6^{\circ} \mathrm{C}\right)$. In order to check progress of the reaction at room temperature $\left(25 \pm 3^{\circ} \mathrm{C}\right)$, other two sets $\left(1.0 \mathrm{~mL}\right.$ of $0.1 \mathrm{~mol} \mathrm{~L}^{-1}$ glycine + ribose solution with/without $5 \mathrm{mg}$ of goethite) were prepared and left in the room for 4 days and 8 days. The supernatants of the product solutions were diluted 100 times by pure water (MilliQ) in order to prevent spectral saturation.

$3 \mathrm{~mL}$ of the diluted solutions were measured in a quartz cell (optical pass length: $10 \mathrm{~mm}$ ) by an UV-VIS spectrometer (V-570, Jasco). UV-VIS spectra were measured at a scanning speed of $400 \mathrm{~nm}$ per minute with a wavelength resolution of $1.0 \mathrm{~nm}$ in the $200-1100 \mathrm{~nm}$ spectral range.

\section{ATR-IR measurements of the reactants and products on goethite}

In order to examine adsorption on goethite of the reactants of the simulated Maillard reaction, ATR-IR measurements were conducted by an FT-IR spectrometer (VIR9500, Jasco) with an ATR attachment (Specac horizontal ATR with a ZnSe crystal, about 5 times reflection) (Fig. 1). In the ATR-IR method, IR beam (evanescent waves) penetrates in the order of several hundreds of $\mathrm{nm}$ at the interface between the ATR crystal and the sample on it and an absorption-like IR spectrum can be obtained from the sample [30]. Since penetration depth depends on wavenumber and optical path length is difficult to be normalized, ATR-IR signals at different wavenumbers cannot be compared in the same way as absorbance spectra. In this study, pATR $=-\log _{10} I / I_{0}$ ( $I$ : reflection intensity, $I_{0}$ : incident intensity) values ("p" means " $-\log$ ") is employed for the vertical axis of ATR-IR spectra following Masuda et al. [31]. In this study, thin layers of goethite were made on the ATR crystal (ZnSe), and IR spectral changes with time of the reactant solution on the goethite layer were measured.

The thin layer of goethite was made on the ATR crystal (ZnSe) in reference to Hug (1997) [32] and Luengo et al. (2006) [33], as follows: $1.0 \mathrm{~mL}$ of pure water was pipetted onto the crystal, and $0.8 \mathrm{~mL}$ was removed to obtain thin water layer on the crystal. Then $0.8 \mathrm{~mL}$ of a $10 \mathrm{~g} \mathrm{~L}^{-1}$ goethite suspension was pipetted onto the crystal and mixed by using the pipette tip. After air-drying at room temperature for $2 \mathrm{~h}$, the ATR surface was rinsed by

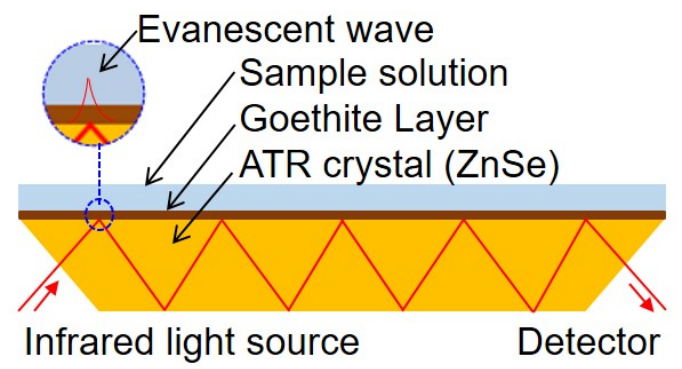

FIG. 1. A schematic figure of the attenuated total reflection (ATR) crystal (ZnSe) with thin layers of goethite used in ATRIR measurements. 
(a)

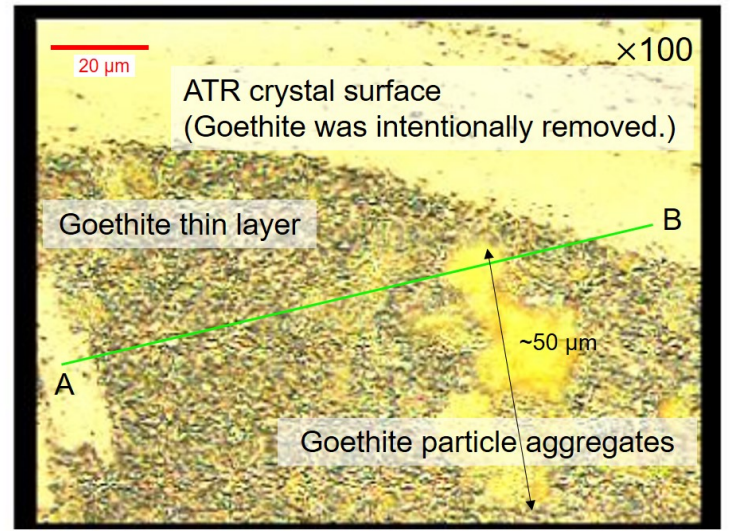

(b) 4

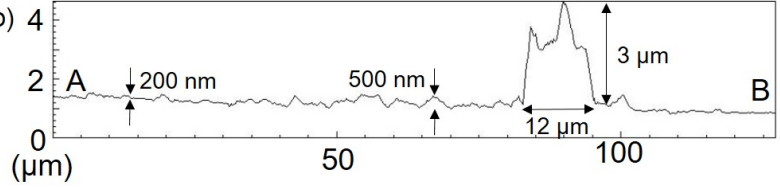

FIG. 2. (a) A representative laser scanning confocal microscope (LSCM) image of goethite layer on an ATR crystal $(\mathrm{ZnSe})$ (objective lens: $\times 100)$ and $(\mathrm{b})$ height profile on a line segment A-B. Particle aggregates of about $3 \mu \mathrm{m}$ thick and a thinner layer of a few hundred $\mathrm{nm}$ are recognized.

pure water twice in order to remove excess goethite. After the second air-drying, thin layer of goethite was obtained on the ZnSe crystal (Fig. 1). The deposited goethite layer on the ATR crystal was observed by laser scanning confocal microscopy (LSCM). A line profile for surface heights of the goethite layer on the ATR crystal (line A-B in Fig. 2) show height differences of $200 \mathrm{~nm}$ to $500 \mathrm{~nm}$ corresponding to thin layers of a few hundred $\mathrm{nm}(<1 \mu \mathrm{m})$. Some large particle aggregates of $10-50 \mu \mathrm{m}$ in size with heights of about $3 \mu \mathrm{m}$ can also be recognized (Fig. 2). The goethite layer is mostly thinner than the penetration depth of evanescent waves in the order of several hundred nm. Therefore, ATR-IR spectra can include both solutes dissolved in water nearby the goethite surface and those adsorbed on goethite surfaces besides goethite layer itself.

$1.0 \mathrm{~mL}$ of the reactant solution $\left(0.1 \mathrm{~mol} \mathrm{~L}^{-1}\right.$ glycine plus $0.1 \mathrm{~mol} \mathrm{~L}^{-1}$ ribose solution) was pipetted onto the ATR crystal with the goethite layer and its IR spectral changes with time were measured every $150 \mathrm{~s}$ for $10800 \mathrm{~s}$ $(3 \mathrm{~h})$ at room temperature $\left(25 \pm 3^{\circ} \mathrm{C}\right)$. As a control experiment, IR spectral changes with time of the reactant solution on the ATR crystal without the goethite layer was also measured every $150 \mathrm{~s}$ for $10800 \mathrm{~s}(3 \mathrm{~h})$. For peak attribution, ATR-IR spectra for $0.1 \mathrm{~mol} \mathrm{~L}^{-1}$ glycine solution, $0.1 \mathrm{~mol} \mathrm{~L}^{-1}$ ribose solution and solvent water without the goethite layer were also measured independently. All the IR spectral measurements were accumulated for 64 scans with a wavenumber resolution of $4 \mathrm{~cm}^{-1}$ in the 650 $4000 \mathrm{~cm}^{-1}$ spectral range. It should be noted that amount of water vapor on the optical path in the spectrometer can change depending on ambient humidity and bring small fine peaks on measured spectra in the $1300-1800 \mathrm{~cm}^{-1}$ region. In this study, these peaks were removed from sample spectra by subtracting an spectrum for water vapor so as for a representative vapor peak height at $1845 \mathrm{~cm}^{-1}$ (baseline: $1839-1853 \mathrm{~cm}^{-1}$ ) to become zero.
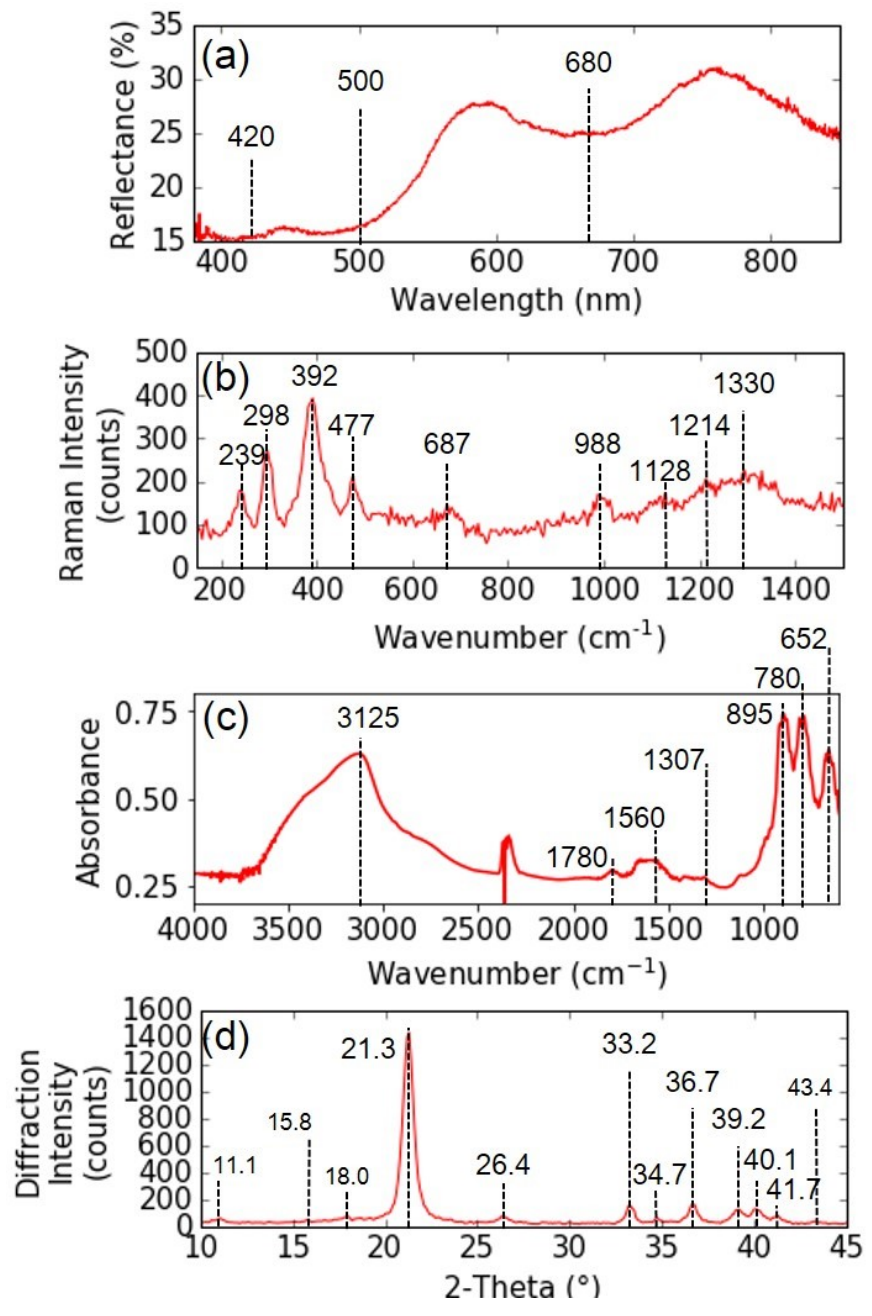

FIG. 3. (a) A representative visible reflectance spectrum, (b) a representative Raman spectrum, (c) a representative IR transflection (transmission-reflection) spectrum and (d) X-ray diffraction pattern, for the obtained iron hydroxide sample indicating mainly goethite.

\section{RESULTS AND DISCUSSION}

\section{A. Identification of the precipitated iron hydroxide}

A representative visible reflectance spectrum of the obtained iron hydroxide sample is shown in Fig. 3(a). Three absorption bands around 420,500, and $680 \mathrm{~nm}$ [indicated in Fig. 3(a)] were recognized in all the obtained visible spectra. These bands were similar to reported absorption bands of goethite by Onga and Nakashima (2014) [26].

Raman spectra of the same sample showed peaks at $392 \mathrm{~cm}^{-1}$ and $687 \mathrm{~cm}^{-1}$ [Fig. 3(b)] [26]. They correspond to reported peaks of goethite at $392 \mathrm{~cm}^{-1}$ and $682 \mathrm{~cm}^{-1}$. The other peaks at 239, 298, 477, 988, 1128, 1214 , and $1330 \mathrm{~cm}^{-1}$ could not be assigned but did not correspond to reported peaks of ferrihydrite, lepidocrocite and hematite [26]. Therefore, the obtained iron hydroxides are mainly composed of goethite.

An IR transflection (transmission-reflection) spectrum of the obtained iron hydroxide sample is shown in Fig. 3(c). Absorption bands at 652, 780, 895, and $3125 \mathrm{~cm}^{-1}$ can be recognized in all of the IR spectra 


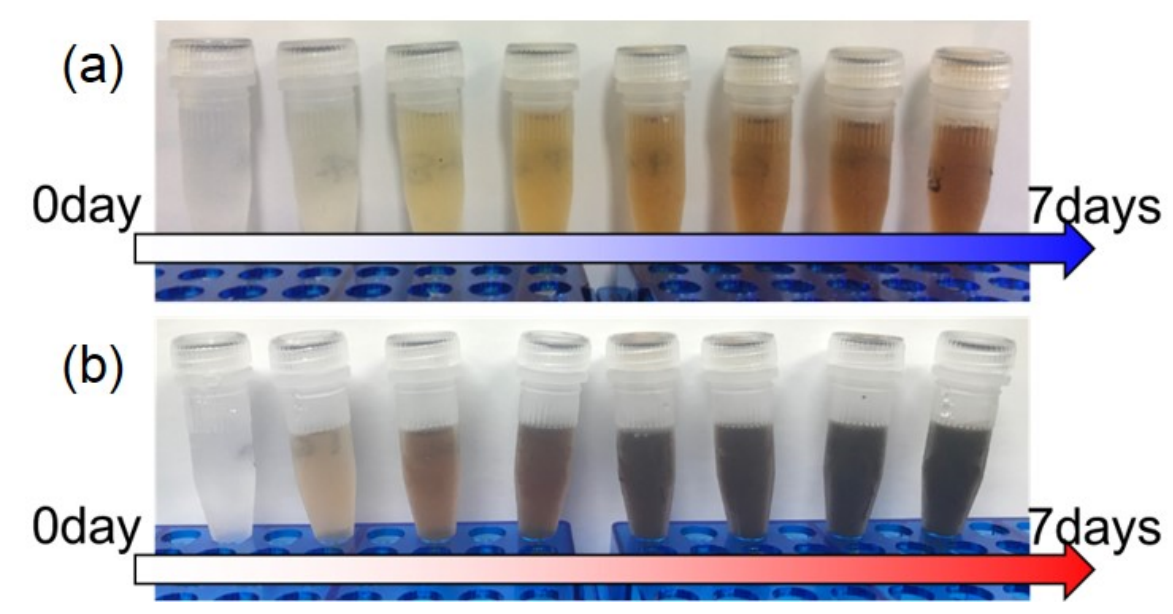

FIG. 4. Photographs of the sample solution of (a) $0.1 \mathrm{~mol} \mathrm{~L}^{-1}$ glycine + ribose solutions without goethite (the control group) heated at $80^{\circ} \mathrm{C}$ for $0-7$ days and (b) $0.1 \mathrm{~mol} \mathrm{~L}^{-1}$ glycine + ribose solutions with goethite suspensions (the experimental group) heated at $80^{\circ} \mathrm{C}$ for $0-7$ days.

obtained in the present study and correspond to those for goethite reported by Nagano et al. (1992) [34]. Weaker bands at $1200-1900 \mathrm{~cm}^{-1}$ (e.g. 1307, 1560, and $1780 \mathrm{~cm}^{-1}$ ) are considered to be due to overtones and combinations of the goethite fundamental bands such as 652,780 , and $895 \mathrm{~cm}^{-1}$.

X-ray diffraction pattern of the iron hydroxide showed six dominant peaks at $2 \theta=21.3^{\circ}, 26.4^{\circ}, 33.2^{\circ}, 34.7^{\circ}$, $36.7^{\circ}, 39.2^{\circ}, 40.1^{\circ}$, and $41.3^{\circ}$ [Fig. $3(\mathrm{~d})$ ]. They correspond to reported peaks of goethite by Nagano et al. (1992) [34]. The other weaker peaks at $2 \theta=11.1^{\circ}, 15.8^{\circ}, 18.0^{\circ}$, and $43.4^{\circ}$ could not be assigned.

Based on these results by visible, Raman and IR microspectroscopy and X-ray diffraction, the obtained precipitates contain some unidentified impurities but are mainly composed of goethite.

\section{B. The simulated Maillard reaction progress in the presence/absence of goethite}

The photograph of the sample solution of $0.1 \mathrm{~mol} \mathrm{~L}^{-1}$ glycine + ribose solutions without goethite (the control group) heated at $80^{\circ} \mathrm{C}$ for $0-7$ days is shown in Fig. 4(a). The product solutions became more yellow-brownish with increasing heating duration.

The photograph of the sample solution of $0.1 \mathrm{~mol} \mathrm{~L}^{-1}$ glycine + ribose solutions with goethite suspensions (the experimental group) heated at $80^{\circ} \mathrm{C}$ for $0-7$ days is also shown in Fig. 4(b). The product solutions show darker colors than the control group for all the heating durations.

UV-VIS spectra for these product solutions (diluted 100 times) are shown in Fig. 5. A band around $280 \mathrm{~nm}$ increased with time and absorbance at shorter wavelength increased more for longer heating durations. These spectral changes suggest progress of the simulated Maillard reaction [22]. For the experimental group, the absorption intensities in the ultraviolet to visible wavelength region are generally larger and shapes of bands around $280 \mathrm{~nm}$ are slightly different from those for the control group [Fig. 5(b)].

In order to show quantitative differences in absorption
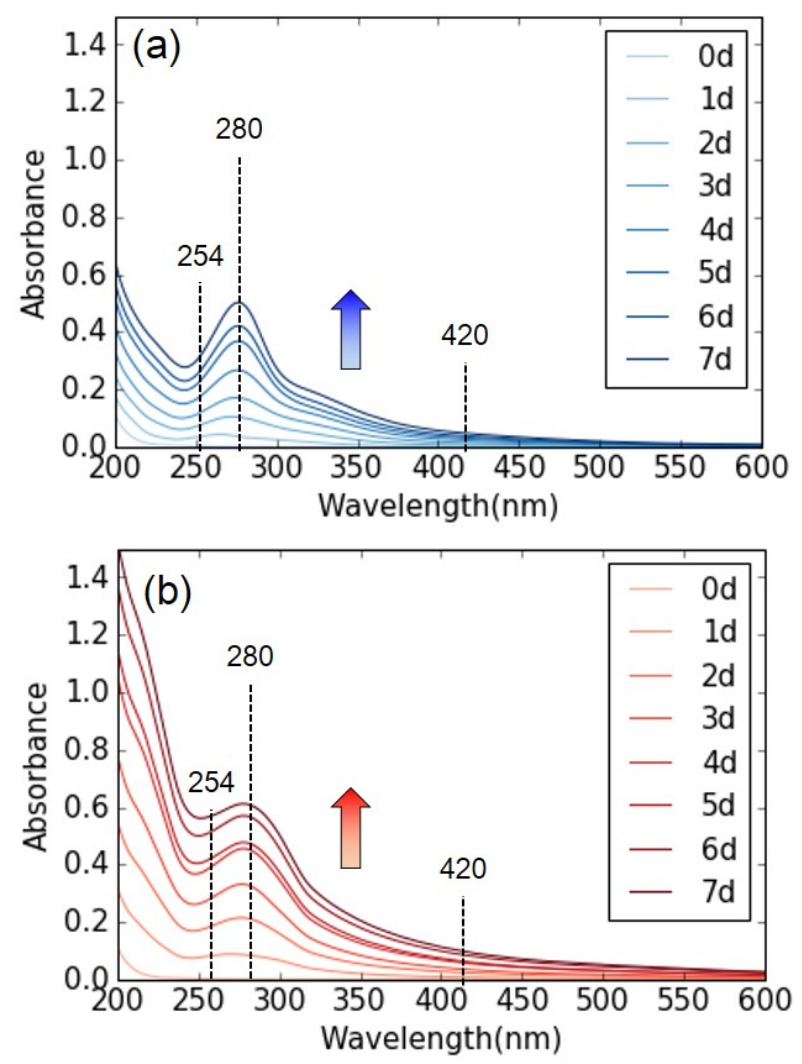

FIG. 5. Ultraviolet-visible (UV-VIS) spectra for (a) product solutions without goethite (control group) and (b) product solutions with goethite (experimental group) heated at $80^{\circ} \mathrm{C}$ for $0-7$ days (diluted 100 times). $0,1,2,3,4,5,6$, and 7 days spectra are shown.

intensities with and without goethite, absorption intensities at $254 \mathrm{~nm}$ and $420 \mathrm{~nm}$ were determined as peak heights with a one-point base at $600 \mathrm{~nm}$. Absorptions at $254 \mathrm{~nm}$ and $420 \mathrm{~nm}$ have been often used as quantitative indicators for amounts of dissolved organic matter in water $(254 \mathrm{~nm})[22,35]$ and browning degree in the Maillard reaction processes $(420 \mathrm{~nm})$ [36]. These absorption bands do not necessarily have clear single peaks be- 


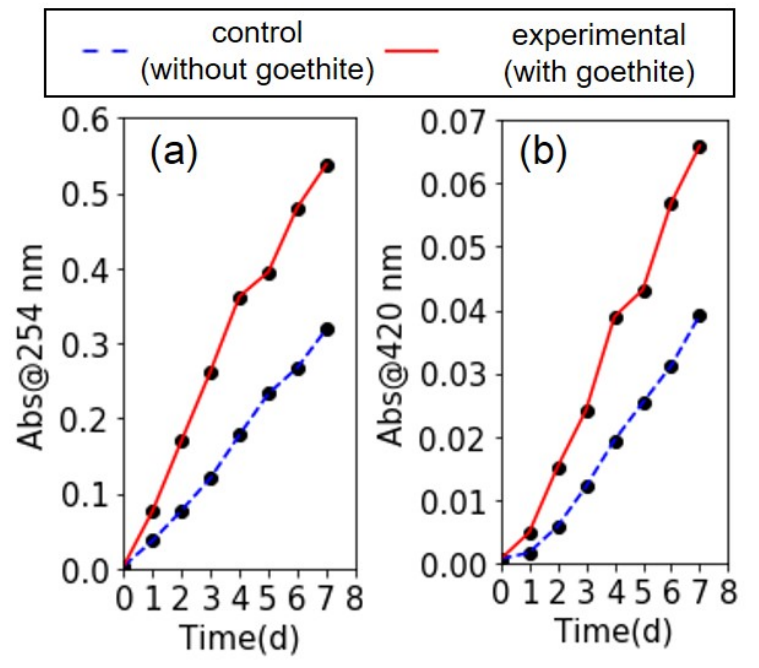

FIG. 6. Changes with time (0-7 days) of (a) absorption intensities at $254 \mathrm{~nm}$ with a one-point base at $600 \mathrm{~nm}$ and (b) absorption intensities at $420 \mathrm{~nm}$ with a one-point base at $600 \mathrm{~nm}$ for product solutions with/without goethite (experimental/control group) heated at $80^{\circ} \mathrm{C}$ for $0-7$ days (diluted 100 times).

cause of complex mixtures of multiple absorption bands in the ultraviolet range. The $254 \mathrm{~nm}$ and $420 \mathrm{~nm}$ absorbance with goethite are consistently larger than those without goethite [Fig. 6(a, b)]. These results indicate enhancement of formation of humic-like [22] and brown [36] products, respectively. It should be noted that completion of the Maillard reaction is difficult to define in this experimental duration because it is a series of continuous reactions including products' polymerization taking long durations even at high temperatures [22].

On the other hand, for product solutions without/with goethite (control/experimental group) left at room temperature $\left(25 \pm 3^{\circ} \mathrm{C}\right)$ for 4 days and 8 days (diluted 100 times), absorption intensities at $254 \mathrm{~nm}$ and $420 \mathrm{~nm}$ with a one-point base at $600 \mathrm{~nm}$ showed only very small changes $(<0.001$ for $254 \mathrm{~nm}$ absorbance and $<0.0003$ for $420 \mathrm{~nm}$ absorbance), which are much smaller than those heated at $80^{\circ} \mathrm{C}$ (Fig. 6). These results can be understood by very slow reactions around $25^{\circ} \mathrm{C}$ extrapolated from our previous kinetic experiments at $60-80^{\circ} \mathrm{C}[22]$ : $96.6 \mathrm{~kJ} \mathrm{~mol}^{-1}$ of activation energy and $7.68 \times 10^{8} \mathrm{~s}^{-1}$ of frequency factor for an apparent first-order kinetic analysis of increases of absorption intensity at $254 \mathrm{~nm}$ with a one-point base at $600 \mathrm{~nm}$ during the simulated Maillard reaction of $0.1 \mathrm{~mol} \mathrm{~L}^{-1}$ glycine + ribose solutions heated at $60-80^{\circ} \mathrm{C}$ for $144 \mathrm{~h}$. For kinetic understanding for the catalytic enhancement, we need additional experiments at high temperatures for longer durations in future studies.

The absorption band at $280 \mathrm{~nm}$ is considered to be due to furfural-like intermediates during the Maillard reaction [22]. Since the band shape was changed by the presence of goethite (Fig. 5), intermediates formed with goethite can be different from those without goethite. Therefore, reaction pathways might be changed by the presence of goethite.

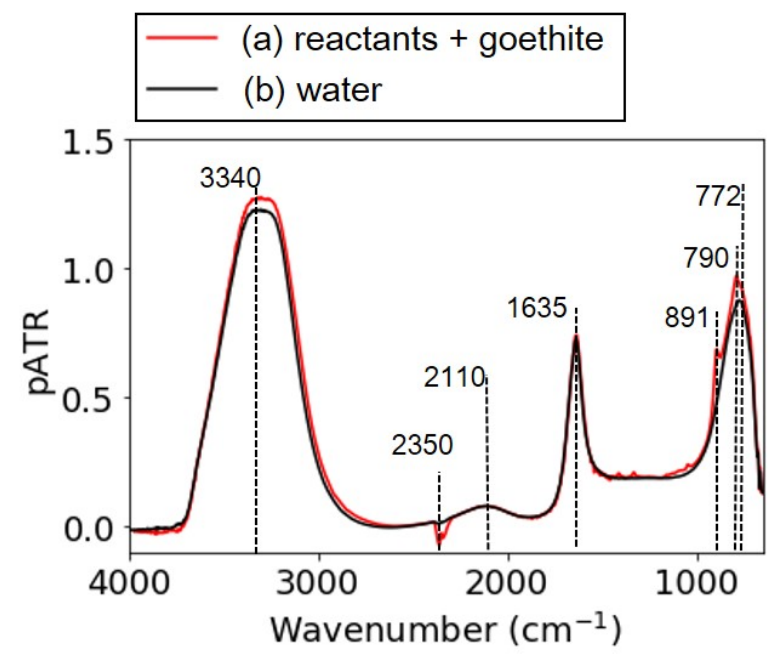

FIG. 7. Raw pATR infrared (IR) spectra for (a) the reactant solution with the goethite layer $\left(0.1 \mathrm{~mol} \mathrm{~L}^{-1}\right.$ glycine + ribose solution) (red) and (b) pure water (black).

\section{ATR-IR measurements of the reactants on goethite}

ATR-IR spectra were measured for the reactant solutions (0.1 mol L $\mathrm{L}^{-1}$ glycine + ribose solutions) with/without the goethite layer. Raw pATR spectra $\left(\mathrm{pATR}=-\log I / I_{0} ; I\right.$ : reflection intensity, $I_{0}$ : incident intensity [31]) for (a) the reactant solution with the goethite layer and (b) pure water without the goethite layer are shown in Fig. 7. They showed water absorptions around $772,1635,2110$, and $3340 \mathrm{~cm}^{-1}$ and an absorption around $2350 \mathrm{~cm}^{-1}$ due to $\mathrm{CO}_{2}$ on the optical path in the spectrometer [21, 28, 31]. The spectrum (a) also showed goethite absorption peaks at $790 \mathrm{~cm}^{-1}$ and $891 \mathrm{~cm}^{-1}$. These are mostly similar to those in IR transflection (transmission-reflection) spectrum of goethite [Fig. 3(c)]. However, the peak position for goethite by ATR-IR is slightly different from that by transflection method [895 $\mathrm{cm}^{-1}$ for Fig. 3(c) vs. $891 \mathrm{~cm}^{-1}$ in Fig. 7(a)]. These differences are originated from distortion of absorption bands by ATR-IR due to differences with wavenumber in penetration depths of evanescent waves [31]. The goethite absorptions at $652 \mathrm{~cm}^{-1}$ and $3125 \mathrm{~cm}^{-1}$ [Fig. 3(c)] were possibly masked with the strong absorptions by water. Smaller peaks around $1000-1600 \mathrm{~cm}^{-1}$ on the spectrum (a) were by the reactants.

Subtracting the water spectrum from an aqueous solution spectrum can provide an ATR-IR spectrum of solutes. In the following, solution spectra subtracted by pure water will be presented. The reactant solution on the goethite layer showed peaks at 1010, 1044, 1088, $1120,1156,1226,1246,1330,1410,1442,1510,1630$, and $1780 \mathrm{~cm}^{-1}$ [Fig. $8(\mathrm{R}+\mathrm{g})$ ]. The reactant solution without the goethite layers showed absorption peaks at 1010 , 1044, 1088, 1120, 1156, 1226, 1246, 1330, 1410, 1442, 1510, 1630, and $1740 \mathrm{~cm}^{-1}$ [Fig. 8(R)]. The glycine solution showed absorption peaks at 1030, 1130, 1330, 1410, 1442, 1510, and $1630 \mathrm{~cm}^{-1}$ [Fig. 8(gly)]. The ribose solution showed absorption peaks at 1010, 1044, 1088, 1120, 1156, 1226, 1246, 1348, and $1442 \mathrm{~cm}-1$ [Fig. 8(rib)]. 


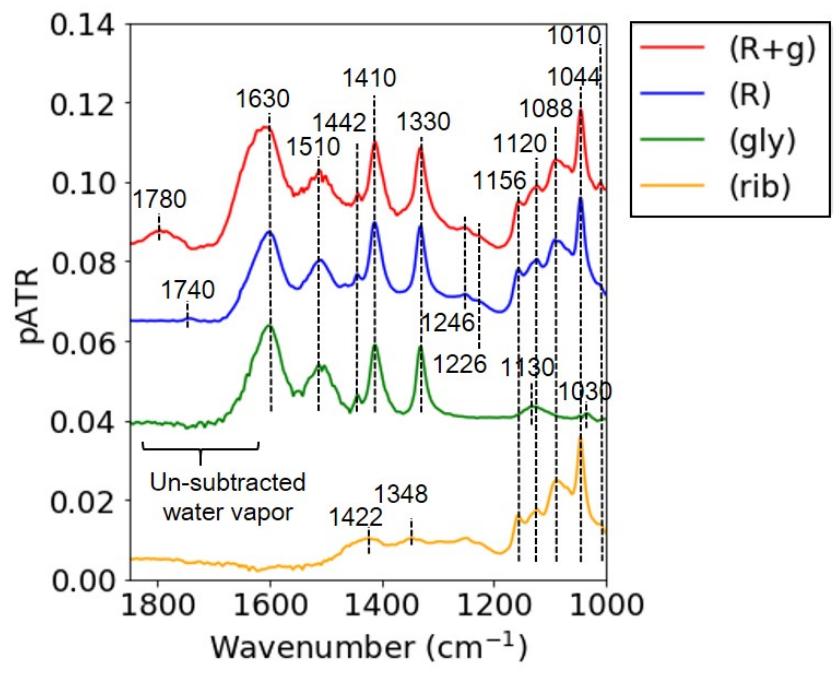

FIG. 8. Difference ATR-IR spectra from the pure water spectrum for the reactants with the goethite layer $(R+g)$. $(R)$ : the reactants without goethite. (gly): glycine only. (rib): ribose only.

In Fig. $8(\mathrm{R}+\mathrm{g}, \mathrm{R})$, the glycine peaks at $1030 \mathrm{~cm}^{-1}$ and $1130 \mathrm{~cm}^{-1}$ [Fig. 8(gly)] and the ribose peaks $1348 \mathrm{~cm}^{-1}$ and $1422 \mathrm{~cm}^{-1}$ [Fig. 8(rib)] are considered to be hidden by the larger peaks. Smaller fine peaks in the $1600-1800 \mathrm{~cm}^{-1}$ region (i.e. clearly visible peaks around $1700 \mathrm{~cm}^{-1}$ in Fig. 8(gly), as indicated) are due to water vapor which remained after subtraction of pure water.

Figure $8(\mathrm{R}+\mathrm{g}, \mathrm{R}$, gly) shows the glycine peak at $1510 \mathrm{~cm}^{-1}$ originated from amino group $\left(-\mathrm{NH}_{3}^{+}\right)$and the peaks at $1330 \mathrm{~cm}^{-1}$ and $1442 \mathrm{~cm}^{-1}$ originated from methyl group $\left(>\mathrm{CH}_{2}\right)[21,37,38]$. The peaks at $1410 \mathrm{~cm}^{-1}$ and $1630 \mathrm{~cm}^{-1}$ [Fig. $8(\mathrm{R}+\mathrm{g}, \mathrm{R}$, gly $)$ ] can be due to symmetric and asymmetric stretching of $\mathrm{COO}^{-}$of glycine, and the later possibly includes a reported peak by amino groups of glycine at $1600 \mathrm{~cm}^{-1}$ [38]. The peaks at $1030 \mathrm{~cm}^{-1}$ and $1130 \mathrm{~cm}^{-1}$ [Fig. 8(gly)] can be assigned to $\mathrm{C}-\mathrm{N}$ and $-\mathrm{NH}_{3}^{+}$of glycine, respectively [38]. The peak at $1740 \mathrm{~cm}^{-1}$ [Fig. $8(\mathrm{R})$ ] can be due to $\mathrm{C}=\mathrm{O}$ stretching of $\mathrm{COOH}$ group $[39,40]$. The ribose peaks at 1044 , 1088, 1120, and $1156 \mathrm{~cm}^{-1}$ [Fig .8(R+g, R, rib $\left.)\right]$ can be possibly originated from $\mathrm{C}-\mathrm{O}$ bonds $[21,41]$. Some reported peaks by ribose can be recognized at 1010, 1226 , 1246, 1348, and $1422 \mathrm{~cm}^{-1}$ [Fig. 8(rib)] [42]. The peak at $1780 \mathrm{~cm}^{-1}$ can be due to an overtone of the goethite peak at $895 \mathrm{~cm}^{-1}$ [Fig. 3(c)]. It should be noted that the other overtones and combinations of the goethite fundamental bands such as 652,780 , and $895 \mathrm{~cm}^{-1}$ can overlap the reactants' bands around $1200-1700 \mathrm{~cm}^{-1}$.

In order to examine changes with time of the ATRIR spectra for the reactant solutions with/without the goethite layer, they are shown as difference spectra from the starting spectra $(t=0 \mathrm{~h})$ for showing only time dependent changes removing contribution from the goethite layer.

Representative difference spectra from $t=0$ spectrum for $(\mathrm{R})$ the reactant solution without goethite [Fig. 9(R)] at $t=0,1,2$, and $3 \mathrm{~h}$ show only a few changes due to water vapor. On the other hand, representative difference spectra from $t=0$ spectrum for $(\mathrm{R}+\mathrm{g})$ the reactant so-

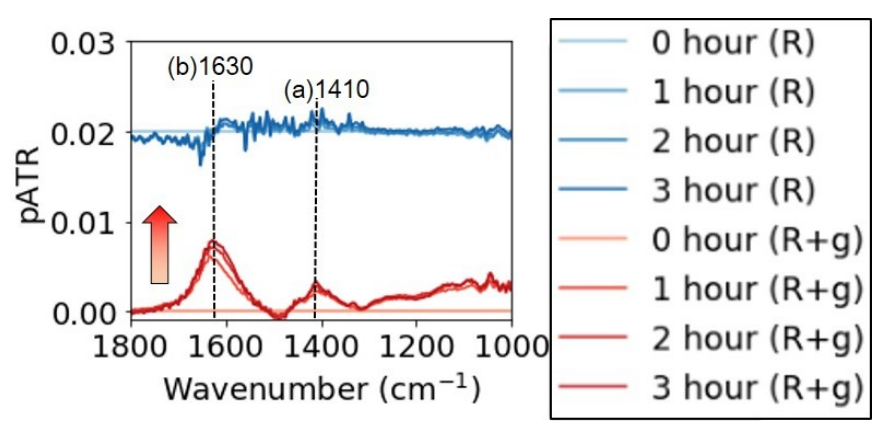

FIG. 9. Representative difference IR spectra $(t=0,1,2$, and $3 \mathrm{~h}$ ) from $t=0$ spectrum for $(\mathrm{R})$ the reactant solution without goethite and $(\mathrm{R}+\mathrm{g})$ the reactant solution on goethite.

lution with goethite [Fig. $9(\mathrm{R}+\mathrm{g})]$ show larger increases of bands at $1410 \mathrm{~cm}^{-1}$ (a) and $1630 \mathrm{~cm}^{-1}$ (b) than that without goethite. The peak at $1410 \mathrm{~cm}^{-1}$ (a) is due to asymmetric stretching of $\mathrm{COO}^{-}$of glycine [Fig. 8(R)], and the peak at $1630 \mathrm{~cm}^{-1}$ (b) is due to symmetric stretching of $\mathrm{COO}^{-}$of glycine [Fig. $8(\mathrm{R})$ ].

In order to show quantitatively these increases, changes with time of band areas around (a) $1410 \mathrm{~cm}^{-1}$ and (b) $1630 \mathrm{~cm}^{-1}$ (baselines: $1330-1500 \mathrm{~cm}^{-1}$ and 1500 $1800 \mathrm{~cm}^{-1}$, respectively) in the $(\mathrm{R})$ and $(\mathrm{R}+\mathrm{g})$ spectra (Fig. 9) are plotted in Fig. 10.

Band area at $1410 \mathrm{~cm}^{-1}$ and $1630 \mathrm{~cm}^{-1}$ [Fig. 10(a, b)] showed little changes for the reactants only without goethite $(\mathrm{R})$. This suggests that increases in the concentration of components with $\mathrm{COO}^{-}$functional groups due to water evaporation were minor in the experimental duration. Slightly negative band areas can be due to fluctuation of unsubtracted fine peaks of water vapor. On the other hand, band areas around $1410 \mathrm{~cm}^{-1}$ and $1630 \mathrm{~cm}^{-1}$ [Fig. 10(a, b)] for the reactants with goethite $(\mathrm{R}+\mathrm{g})$ clearly increased within a few hours with some small fluctuations.

The goethite surface is reported to be charged positively with mainly surface $\mathrm{Fe}-\mathrm{OH}_{2}^{+}$groups under $\mathrm{pH}$ conditions of our study (the reactant solution: $\mathrm{pH}=5.8$ ) [16]. Therefore, negatively charged $\mathrm{COO}^{-}$groups can be

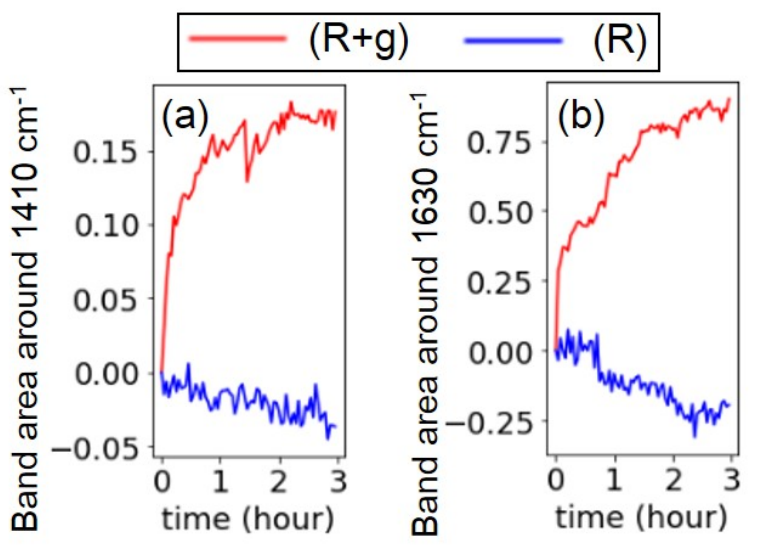

FIG. 10. Changes with time $(0-3 \mathrm{~h})$ of ATR-IR band areas around (a) $1410 \mathrm{~cm}^{-1}$ and (b) $1630 \mathrm{~cm}^{-1}$ (baselines: 1330 $1500 \mathrm{~cm}^{-1}$ and $1500-1800 \mathrm{~cm}^{-1}$, respectively) in the (R) and $(\mathrm{R}+\mathrm{g})$ spectra in Fig. 9. 
easily attracted on the goethite surface. This adsorption of $\mathrm{COO}^{-}$-bearing components onto the goethite layer is considered to occur in a few hours even at room temperature.

In the above section, the time scales for the simulated Maillard reaction progress are suggested to be more than several days at $80^{\circ} \mathrm{C}$ (Fig. 6) and can be far much longer at room temperature. It should be noted that the enhancement of reaction progress in the presence of goethite occurred already within a day (Fig. 6). On the other hand, adsorption of the reactant glycine onto goethite occurred within a few hours at room temperature (Fig. 10). Therefore, later processes on the goethite surface after the fast adsorption are necessary for the reaction enhancement. They can be possibly due to acceleration of association of glycine and ribose forming reaction intermediates by higher concentrations of the reactant glycine on the goethite surface.

As another mechanism of the reaction enhancement, adsorption of the intermediates should also be considered. Since the Maillard reaction includes formation of carboxyl group by oxidation of hydroxyl groups on carbon (-C$\mathrm{OH})[43]$, the product solution can include $\mathrm{COO}^{-}$bearing components which are not originated from glycine. They would make $\mathrm{pH}$ of the product solution lower than the reactant solution and be responsible for more positively charged goethite surface $\left(\mathrm{Fe}-\mathrm{OH}_{2}^{+}\right)$.

In order to understand detailed surface processes, kinetic ATR-IR measurements at goethite surfaces at different temperatures $\left(20-80^{\circ} \mathrm{C}\right)$ are necessary in the future studies. We have designed and constructed a new in situ heatable ATR-IR cell with smaller fluctuations of water vapor and solvent evaporations, for precise quantitative monitoring of surface processes.

\section{CONCLUSIONS}

In order to examine progress of the simulated Maillard reaction in the presence/absence of goethite, ultravioletvisible spectra for the simulated Maillard reaction products by glycine and ribose heated at $80^{\circ} \mathrm{C}$ for 7 days with/without goethite were measured. The larger $254 \mathrm{~nm}$ and $420 \mathrm{~nm}$ absorption intensities for the product solution with goethite than the control group without goethite might suggest catalytic enhancement on goethite of humic-like products formation and browning, respectively.

For direct monitoring for adsorption of reactants of the simulated Maillard reaction onto goethite, a thin layer of goethite was made on the ATR crystal (ZnSe) and ATRIR spectral changes with time for the reactant solution on the goethite layer were measured every $150 \mathrm{~s}$ for $3 \mathrm{~h}$ at room temperature. Increases of band areas around $1410 \mathrm{~cm}^{-1}$ and $1630 \mathrm{~cm}^{-1}$ suggested fast adsorption of components with $\mathrm{COO}^{-}$groups on positively charged goethite surface. These adsorption processes within a few hours are faster than formation enhancement on goethite of humic-like and brown products in several days. A heatable ATR-IR cell under development can be used for further detailed kinetic studies of surface processes on goethite layers at different temperatures $\left(20-80^{\circ} \mathrm{C}\right)$.

\section{ACKNOWLEDGMENTS}

This work was supported by JSPS KAKENHI Grant Number JP18J10249. YN has been supported by Research Assistantship of the Graduate School of Science, Osaka University from June 16, 2017 to March 31, 2018.
[1] J. E. Rothman and J. Lenard, Science 195, 743 (1977).

[2] R. Wang, K. Hashimoto, A. Fujishima, M. Chikuni, E. Kojima, A. Kitamura, M. Shimohigoshi, and T. Watanabe, Nature 388, 431 (1997).

[3] T. Minato and T. Abe, Prog. Surf. Sci. 92, 240 (2017).

[4] A. J. Gellman and N. D. Spencer, Proc. Inst. Mech. Eng. J 216, 443 (2002).

[5] C. D. Dimitrakopoulos and P. R. L. Malenfant, Adv. Mater. 14, 99 (2002)

[6] S. Nakashima, C. J. Spiers, L. Mercury, P. Fenter, and M. H. Hochella, Jr., in: Physicochemistry of Water in Geological and Biological Systems: Structures and Properties of Thin Aqueous Films, edited by S. Nakashima, C. J. Spiers, L. Mercury, P. Fenter, and M. H. Hochella, Jr. (Universal Academy Press, Inc., Tokyo, 2004) p. 1.

[7] M. R. Hoffmann, in: Aquatic Chemical Kinetics: Reaction Rates of Processes in Natural Waters, edited by W. Stumm (John Wiley \& Sons, New York, 1990) p. 71.

[8] B. Wehrli, in: Aquatic Chemical Kinetics: Reaction Rates of Processes in Natural Waters, edited by W. Stumm (John Wiley \& Sons, New York, 1990) p. 311.

[9] B. Sulzberger, in: Aquatic Chemical Kinetics: Reaction Rates of Processes in Natural Waters, edited by W. Stumm (John Wiley \& Sons, New York, 1990) p. 401.

[10] T. Otsuka and S. Nakashima, J. Mineral. Petrol. Sci. 102, 302 (2007).

[11] F. J. Stevenson, Humus Chemistry: Genesis, Composi- tion, Reactions, 2nd ed. (Wiley, New York, 1994).

[12] W. Kördel, M. Dassenakis, J. Lintelmann, and S. Padberg, Pure Appl. Chem. 69, 1571 (1997).

[13] L. Weng, W. H. van Riemsdijk, L. K. Koopal, and T. Hiemstra, Environ. Sci. Technol. 40, 7494 (2006).

[14] S. Hillier, Clays Miner. 35, 291 (2000).

[15] R. M. Cornell and U. Schwertmann, The Iron Oxides: Structure, Properties, Reactions, Occurrences and Uses (VCH, Weinheim, 1996).

[16] W. A. Zeltner and M. A. Anderson, Langmuir 4, 469 (1988).

[17] L. C. Maillard, Comptes Rendus Acad. Sci. 154, 66 (1912).

[18] P. A. Finot, Ann. N. Y. Acad. Sci. 1043, 1 (2005).

[19] S. Yamamoto and R. Ishiwatari. Org. Geochem. 14, 479 (1989).

[20] P. H Abelson, Annu. Rev. Earth Planet. Sci. 6, 325 (1978).

[21] Y. Nakaya and S. Nakashima, Chem. Lett. 45, 1204 (2016).

[22] Y. Nakaya, S. Nakashima, and M. Moriizumi, Appl. Spectrosc. 72, 1189 (2018).

[23] K. Taguchi and Y. Sampei, Org. Geochem. 10, 1081 (1986).

[24] P. Arfaioli, O. L. Pantini, M. Bosetto, and G. G. Ristori, Clay Miner. 34, 487 (1999).

[25] U. Schwertmann and R. M. Cornell, Iron Oxides in the 
Laboratory: Preparation and Characterization, 2nd ed. (Wiley-VCH, New York, 2000).

[26] C. Onga and S. Nakashima, Appl. Spectrosc. 68, 740 (2014).

[27] R. Tonoue, M. Katsura, M. Hamamoto, H. Bessho, and S. Nakashima, Appl. Spectrosc. 68, 733 (2014).

[28] M. Hamamoto, M. Katsura, N. Nishiyama, R. Tonoue, and S. Nakashima, e-J. Surf. Sci. Nanotechnol. 13, 301 (2015).

[29] S. Kudo, H. Ogawa, E. Yamakita, S. Watanabe, T. Suzuki, and S. Nakashima, Appl. Spectrosc. 71, 1621 (2017).

[30] S. J. Hug and B. Sulzberger, Langmuir 10, 3587 (1994).

[31] K. Masuda, T. Haramaki, S. Nakashima, B. Habert, I. Martinez, and S. Kashiwabara, Appl. Spectrosc. 57, 274 (2003).

[32] S. J. Hug, J. Colloid Interface Sci. 188, 415 (1997).

[33] C. Luengo, M. Brigante, J. Antelo, and M. Avena, J. Colloid Interface Sci. 300, 511 (2006).

[34] T. Nagano, S. Nakashima, S. Nakayama, K. Osada, and M. Senoo, Clays Clay Miner. 40, 600 (1992).
[35] J. K. Edzwald, W. C. Becker, and K. L. Wattier, J. Am. Water Works Assoc. 77, 122 (1985).

[36] J. A. Stamp and T. P. Labuza, J. Food Sci. 48, 543 (1983).

[37] S. Kumar, A. K. Rai, V. B. Singh, and S. B. Rai, Spectrochim. Acta A 61, 2741 (2005).

[38] N. Kitadai, T. Yokoyama, and S. Nakashima, J. Mol. Struct. 981, 179 (2010).

[39] R. M. Silverstein, G. C. Bassler, and T. C. Morrill, Spectrometric Identification of Organic Compounds, 5th ed. (Wiley, New York, 1991).

[40] J.-J. Max, M. Trudel, and C. Chapados, Appl. Spectrosc. 52. 226 (1998).

[41] P. Carmona and M. Molina, J. Raman Spectrosc. 21, 395 (1990).

[42] Y. T. Huang, H. F. Liao, S. L. Wang, and S. Y. Lin, AIMS Biophys. 3, 247 (2016).

[43] R. Ikan, Y. Rubinsztain, A. Nissenbaum, and I. R. Kaplan, in: The Maillard Reaction: Consequences for the Chemical, Life Sciences, edited by R. Ikan (John Wiley \& Sons, Chichester, 1996) p. 1. 